\title{
Viewing cancer pathophysiology as a lead in understanding cardiac and vascular disease mechanisms
}

\author{
John A. Loudon
}

Correspondence: jon.uk1515@gmail.com

CrossMark

$\leftarrow$ Click for updates

Wetherill Park Medical Centre, Suite 101, Stockland Mall, Polding Street, Wetherill Park, Sydney, NSW, 2164 Australia.

\begin{abstract}
This article describes how understanding mechanisms used by cancer cells-both prosurvival (oncogenic) and pro-apoptotic (tumour suppression)-sheds light on important 'cues' for prosurvival and apoptotic pathways employed in the cardiac and vascular system. Commencing with the mevalonate pathway, numerous examples are presented whereby cancer oftentimes foretells an understanding of relevant mechanisms for cardiology. Pathologies such as cardiomyopathies including heart failure, hypertension/ vascular dysfunction, and reaction to ischaemic-reperfusion injury are discussed. Key features emerge in terms of homeostasis within the cardiac and vascular system and the observation that cardiac pathologies do not present in mere isolation but as co-morbidities. Mechanisms resulting in such pathologies are revealed by considering prosurvival versus pro-apoptotic imbalance (homeostatic disturbance). Overall, one may gain an improved foreknowledge of such mechanisms behind these important regulatory paths in cardiology from studying cancer molecular mechanisms.
\end{abstract}

Keywords: Apoptosis, atheroma, cancer, cardiomyopathy, cardioprotection, farnesol, heart failure, hypertension, mevalonate pathway, oncogene, prosurvival factor, tumour suppressor, vascular disease

\section{Introduction}

Recently [1], it was emphasized that cardioprotective mechanisms/factors targeting ischemia/reperfusion (I/R) injury are of pivotal significance and form a "foremost experimental goal"-a 'holy grail' of cardiac and vascular medicine. A model has already been proposed emphasizing that cancer may play a central role for elucidating and indeed forecasting such factors and mechanisms [2]. In that analysis it has been notably demonstrated that cancer and heart tissue react similarly at the molecular level to withstand imposed environmental challenge. In regards this relation, it was stated: "As another feature of the model, ways to better forecast future therapies aimed at augmenting cardioprotective paths is made possible through understanding of pathways used to sustain cancer cells under external challenges." [2]. In effect, this model represents: "... a novel and important 'cross road' between physiology and pathology" [2].

Importantly, not only do prosurvival/cytoprotective pathways match between heart and cancer but also mechanisms relating to tumour suppression/apoptosis and cardiomyocyte damage [2]. Therefore overall, by looking at the cancer prosurvival model 'in reverse' one has a means to better understand and ultimately aid in developing targeted therapeutics for heart/vascular diseases. Along this line, it has been further detailed the notion that cancer may forecast factors in respect to cardioprotection [3]. In this regard, cancer prosurvival factors claudin, CASPR3, CDC42-binding protein kinase beta and dihydropyrimidinaserelated protein 2 (CRMP2) have not been examined in the heart for their relation to cytoprotection. As such, there remains much scope for productive investigation based on cancer for dissecting target factors involved in heart diseases.

This relation between cancer and the heart has been extended from the prosurvival model [2] to show that cancer biomarkers match with those for cardioprotection-a useful tool for cardiology risk assessment [4]. As a follow on from the cancer prosurvival model, cancer survival factors match with hypertension, cardiohypertrophy and atheroma molecular markers. An upset in homeostasis towards progrowth cellular programming may be adverse for the cardiac/vascular system [5].

The purpose of this article is to emphasize and extend the key and recurring message that cancer prosurvival and apoptotic pathways/mechanisms mimic and oftentimes anticipate such 
John A. Loudon, Cardiovascular System 2014,

shared pathways of note within the cardiac and vascular system. Appreciating this shall aid in revealing deficiencies in understanding cardioprotection and heart and vascular diseases in general. Assisting with providing valuable 'cues' for therapies in cardiac and vascular medicine is a central aim of connecting heart-cancer molecular and cell biology mechanisms.

\section{Methodology}

A literature search was performed using the PubMed database through use of key words joined via the Boolean operator 'and' as I have detailed recently [6]. The means of producing novel concepts by bridging seemingly unrelated knowledge fields is known as 'literature-based discovery' (LBD). LBD is based on the hypothesis that two islands/strands of knowledge (concepts) $\mathrm{A}$ and $\mathrm{C}$ may be related to each other if they share a link to an intermediate concept $B$ (the greater the number of shared links between $A$ and $C$, the more probable is the relationship between them). This notion is known as Swanson's 'ABC' model [7] and I use this approach to bring to light the productive connection between cancer (concept A) and the cardiac and vascular system (concept $\mathrm{C}$ ) via shared prosurvival/ apoptotic molecular mechanisms/factors (concept B).

Literature searches employed the following phrases: cancer/ cancer therapy resistance and factor (where the factor is either a prosurvival/oncogene or tumour suppressor); cardioprotection/cardiomyocyte cytoprotection and factor; myocardial ischaemia and factor. Other substituted key terms were hypertension, cardiomyopathy/hypertrophy, heart failure, vascular dysfunction/atheroma. Such searches revealed when the particular factor(s) of interest were initially associated with cancer or heart disease. Mechanistic pathways were explored from the cardiac/vascular context in cancer to determine correlations and timing of discovery to highlight the relationship of cancer signaling pathways and relevance to cardioprotection, cardiac hypertrophy, hypertension, atheroma and heart failure.

\section{Results and discussion}

For ease of presentation, various aspects of the cardiac and vascular system and pathologies are individually highlighted. The 'logic trail' running throughout is aimed to show that cancer provides an adequate resource to appreciate these aspects from a mechanistic and, following on from this, therapeutics standpoint.

\section{Cardioprotection against ischaemia-reperfusion challenge}

In regards the mevalonate pathway [1], it is interesting to note that farnesol is depicted as cardioprotective via a novel protein geranylgeranylation (prenylation) mechanism. It was further indicated that G-proteins, including members of Ras superfamily, are involved in signal transduction of I/R injury and cardioprotection, although their prenylation status has not been examined in this context [1]. My proposition is that prenylation - a post-translational modification - is central in cardioprotection and protein targets are predicted and indeed defined, through examining cancer. Such cancer prosurvival lipid metabolic pathway mechanisms [8] are closely paralleled in the heart. Notably, consistent with this proposition, by inhibiting lipid metabolic paths, particularly the mevalonate pathway, anti-cancer therapeutics are enhanced [8]. Further, in cancer, prosurvival prenylation reactions have been earlier considered to be suited targets for therapies [9]. Inhibiting protein geranylgeranylation and glycosylation (mediated by Dolichol), prosurvival end-products of the mevalonate pathway [1], by lovastatin inhibits erythropoietin-related cell proliferation in cancer [10]. Predictably, interfering with the Dolichol pathway as seen in dolichol kinase deficiency, leads to heart damage - dilated cardiomyopathy [11].

Farnesol demonstrates a ' $U$ ' shaped survival profile in cardio-myocytes, being toxic at higher doses [1]. This factor directs protein prenylation reactions and has a role in Ras activation via prenylation, certainly a key process in cancer [12]. At high concentrations, farnesol appears also toxic in cancer and mechanistically, the toxicity connects with NF-kappa B and MEK1/2-ERK1/2 pathway and endoplasmic reticulum [13]. Overall, a number of these farnesol-related aspects align between cancer and heart - cancer providing a lead or 'cue' for further investigation in the heart context.

Other intriguing parallels are noted. Earlier, manumycin, a farnesylation inhibitor, was proven effective in targeting cancer [14]. Later, urocortin-II cardioprotection was seen to be abolished by manumycin [15] implicating similar mechanism and forecast by cancer. Further, it has been stated that activation of JNK via Rac1 leads to cardiomyocyte cytoprotection [1]. Earlier, the involvement of Rac1 and JNK in oncogenesis was proven [16]. RhoA is cardioprotective [1] and acts via an 'unexpected' role for PKD as a downstream mediator [17]. Earlier in cancer [18], both RhoA and PKD were found to have joint key roles in oncogenesis-thus anticipating the role of PKD in RhoA-mediated cardioprotection.

Numerous other instances exemplify the utility of cancer as a lead in cardioprotection pathway discovery. G-proteincoupled receptors, such as Adenosine $\mathrm{A}_{3}$ receptor, employ adenosine as a key ligand in stimulating cardioprotection [19]. Inhibition of this adenosine receptor is proposed for cancer therapeutics consistent with its prosurvival capacity. Very recently, [20], the Adenosine $\mathrm{A}_{3}$ receptor agonist 2-ClIB-MECA was shown to mediate cardioprotection via what the authors of that work considered as a novel mechanism involving MEK $1 / 2$ (elucidated from targeted U0126 inhibition) and PI3K/Akt. Earlier, [21], adenosine, through $\mathrm{A}_{3}$ receptor, mediated a proliferative/prosurvival effect on colonic cancer cells. Notably, U0126 blocked the agonist 2-CI-IB-MECA induced proliferation- this novel mechanism for the heart being neatly foretold by cancer. Further, the G-protein- coupled opioid receptor forms a notable example. The kappa opioid receptor 
is involved in directing cardiomyocyte cytoprotection [22]. Unsurprisingly, kappa opioid receptors align with oesophageal carcinoma progression [23].

As further examples, A1/Bfl-1, a Bcl-2 family member, is stimulated by prosurvival NF-kappa B to prevent apoptotic release of mitochondrial cyotchrome $c$ thus providing resistance to chemotherapy induced apoptosis [24]. Prosurvival $\mathrm{Bfl}-1$ is expressed in coronary smooth muscle cells on glucose stimulation in diabetes and may represent an adverse mechanism in the vasculature [25]. Later, in the heart itself, Bfl-1 was noted as a potent cardiocytoprotective factor [26]. In preconditioning cardioprotection, prosurvival $\mathrm{Mcl}-1$ - also a Bcl-2 member - acts in a mechanism with STAT3 and NFkappa $\mathrm{B}$ [27]. In the process of oncogenesis this mechanism is mimicked on upregulation of Mcl-1 with NF-kappa $B$ and STAT3 [28].

In various energy/metabolic-related aspects, cancer and heart align, as I have previously highlighted [2]. Inhibiting carnitine palmitoyltransferase I (CPT-1), thus targeting fatty acid oxidation, decreases I/R tolerance in the disease-free animal model context [29]. In cancer, [30], CPT-1 forms a convenient, efficient ATP production system via beta-oxidation of fatty acids for metabolically active and needy cancer cells. As such, it forms a prosurvival mechanism much like CPT forms a survival path in the context of the disease-free heart [29]. Notably earlier, [31], inhibiting CPT-1 in cancer cells led to apoptosis via increasing ceramide and BNIP3 levels. These mechanisms involving CPT have not as yet been explored in the heart and taking the 'cue' from cancer, it may be anticipated that a similar pathway may apply for cardiomyocyte metabolic damage.

Like prenylation [1], S-nitrosylation forms a post translational cardioprotective mechanism. Atorvastatin induces cardioprotection and is infarct sparing via iNOS/Cox-2 - iNOS producing NO which in turn activates prosurvival Cox-2 via $S$-nitrosylation [32] (see Table 5-below). The importance of the involvement of iNOS/Cox-2/S-nitrosylation mechanism is recapitulated in cancer [33]. In this scenario, iNOS/NO increases activity of Cox-2 and leads to chemoresistance. Further, iNOS/NO activate EGFR/Src via S-nitrosylation influencing oncogene prosurvival network: Myc/Akt/STAT3. Such prosurvival machinery and mechanisms in regard $S$-nitrosylation remain to be explored in detail for the heart the 'cue' here for investigation comes from cancer.

Cardioprotection is afforded by NO both via S-nitrosylation as well as via the cGMP/PKG pathway [34]. Not unexpectedly, cancer also uses the NO/cGMP/PKG machinery as a prosurvival mechanism [35].

Ion channels represent a further convincing presentation for the relation of cancer factors to heart disease. The cystic fibrosis transmembrane conductance regulator (CFTR) chloride anion channel maintains a central role in cardioprotection [36], yet earlier was considered as a prosurvival target for cancer therapy [37]. Cardioprotection may be also related to cationic channels such as K(ATP) [38]. In parallel, this cation channel aligns with cancer prosurvival [39] where K(ATP) blockers inhibit cancer cell proliferation.

In short, lipid and general metabolic paths, mitochondrial mechanisms as well as receptor pathways for opioids and cardio-active factors such as adenosine to name a few, all funnel towards demonstrating a close mechanistic cancerheart alignment (Table 1). Therefore this understanding has clear clinical implications in regards appreciating and indeed foretelling cardioprotection against I/R injury.

Table 1. Alignment of mechanisms/factors relating cancer to ischaemic cardioprotection.

\begin{tabular}{|c|c|}
\hline Cancer & Cardioprotection \\
\hline Prenylation $(\text { Farnesol })^{a}$ & Prenylation (Farnesol) $^{a}$ \\
\hline Glycosylation $(\text { Dolichol })^{b}$ & Glycosylation (Dolichol) $)^{b}$ \\
\hline Farnesylation (Manumycin) ${ }^{c}$ & Farnesylation (Manumycin) ${ }^{c}$ \\
\hline $\mathrm{Rac} / \mathrm{JNK}^{d}$ & $\mathrm{Rac} / \mathrm{JNK}^{d}$ \\
\hline RhoA/PKD ${ }^{e}$ & RhoA/PKD ${ }^{e}$ \\
\hline Adenosine $\mathrm{A}_{3}$ receptor/MEK $1 / 2^{f}$ & Adenosine $\mathrm{A}_{3}$ receptor/MEK $1 / 2^{f}$ \\
\hline$k a p p a-$ opioid receptor ${ }^{g}$ & $k a p p a$-opioid receptor ${ }^{g}$ \\
\hline $\mathrm{A} 1-\mathrm{Bfl} 1^{h}$ & $\mathrm{Bfl} 1^{h}$ \\
\hline Mcl1/NF-kappa B/STAT3 ${ }^{i}$ & Mcl1/NF-kappa B/STAT3 ${ }^{i}$ \\
\hline $\begin{array}{l}\text { Carnitine palmitoyl-transferase } \\
\mathrm{I}^{j}\end{array}$ & Carnitine palmitoyl-transferase $\mathrm{I}^{j}$ \\
\hline Nitric oxide/cGMP/PKG ${ }^{k}$ & Nitric oxide/cGMP/PKG ${ }^{k}$ \\
\hline $\begin{array}{l}S \text {-nitrosylation/Cox-2/iNOS/ } \\
\text { nitric oxide }^{l}\end{array}$ & $\begin{array}{l}S \text {-nitrosylation/Cox-2/iNOS/ } \\
\text { nitric oxide }^{l}\end{array}$ \\
\hline Anion channel: CFTR $^{m}$ & Anion channel: CFTR $^{m}$ \\
\hline Cation channel: $\mathrm{K}(\mathrm{ATP})^{n}$ & Cation channel: $\mathrm{K}(\mathrm{ATP})^{n}$ \\
\hline
\end{tabular}

${ }^{\mathrm{a}}$ Prenylation (the addition of hydrophobic moiety to a protein to assist in cell membrane attachment) is a cancer prosurvival mechanism [8,9] and is a suggested mechanism that may lead also to ischaemic cardioprotection [1] with farnesol being an active component of this process.

${ }^{b}$ Dolichol, a product of the mevalonate pathway, mediates glycosylation, a cancer prosurvival mechanism [10] and assists in sustaining myocardial integrity [11].

${ }^{c}$ Farnesylation (prenylation by means of addition of an isoprenyl group) inhibition by manumycin targets cancer [14] and abolishes urocortin-II mediated cardioprotection [15].

$\mathrm{d}$ Rac1-JNK prosurvival cascade is involved in cancer pathophysiology [16] and is also considered to be involved in cardioprotection [1].

${ }^{\mathrm{e}} \mathrm{RhoA}-\mathrm{PKD}$ cascade is a prosurvival feature in cancer $[\mathbf{1 8}]$ as well as in cardioprotection $[\mathbf{1 , 1 7}]$.

${ }_{\mathrm{f}}$ Adenosine A3 receptor controls a prosurvival response in cancer [21] involving MEK1/2 and also mediates cardioprotection via the same mechanism [20].

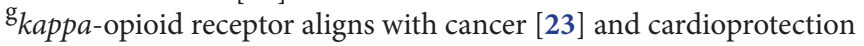
[22].

${ }^{\mathrm{h}} \mathrm{Bfl1}$ (A1-Bfl1) is a prosurvival factor in cancer [24] and prosurvival in the vascular system in the context of diabetes [25] and directly cardiomyocyte cytoprotective [26].

i Cancer employs the prosurvival cascade Mcl1/NF-kappa B/STAT3 [28] with the same cascade operating in cardioprotection [27]. 
John A. Loudon, Cardiovascular System 2014,

${ }^{j}$ Carnitine palmitoyltransferase (CPT-1) forms a metabolic prosurvival mechanism in cancer $[30,31]$ and is metabolically a cardioprotective mechanism [29].

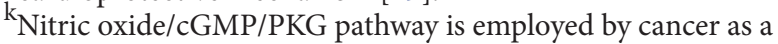
prosurvival mechanism [35] and forms a cardioprotective cascade [34].

${ }^{\mathrm{l}} \mathrm{S}$-nitrosylation/Cox-2/iNOS/nitric oxide forms a cancer-related prosurvival mechanism [33] aligning with cardioprotection [32].

${ }^{\mathrm{m}}$ Anion channel-CFTR forms a cancer prosurvival pathway [37] and represents a cardioprotective mechanism [36].

${ }^{\mathrm{n}}$ Cation channel-K(ATP) represents a cancer prosurvival factor [39] and aligns with cardioprotection [38].

\section{Addressing heart failure}

Not only do prosurvival but also pro-apoptotic cardiac/ vascular mechanisms mechanistically align with cancer [2]. This has significance in heart failure for which biomarkers and mechanisms are highly sought after. For example, dipeptidyl peptidase IV (DPPIV) was found to act via SDF-1 modulation as a tumour suppressor [40]. Mechanistically, SDF-1, as downregulated by DPPIV, was exposed as a regulated prosurvival pathway in cancer [40]. Another prior study, [41] indicated that sanguinarine, a plant derivative, relates to suspected precancerous alterations. This agent is a natural DPPIV inhibitor and assists in explaining a potential oncogenic mechanism [42]. I consider that as a follow-on, sanguinarine is cardioprotective by augmenting SDF levels secondary to DPPIV inhibition.

In heart failure, SDF is beneficial consistent with its prosurvival role [43]. Recently, remote ischaemic preconditioning has been demonstrated to relate to humoral production of SDF-1 with serum levels of DPPIV downregulating this factor [44]. Circulating DPPIV aligns with cardiac dysfunction in heart failure and thus is a suited biomarker and target for same. Such key observations were predicted in cancer from an anti-survival viewpoint (Table 2).

\section{Addressing hypertension and atheroma}

As anticipated, tumour suppression as an anti-survival mechanism counters hypertension which represents, to a significant degree, a vascular smooth muscle progrowth imbalance. Induction of senescence via Nutlin-3a prevents ubiquitin ligase $M D M 2$, a negative regulator, from interacting with the long established tumour suppressor p53, thus leading to inhibition of proliferation of pulmonary arterial smooth muscle cells [45]. Another well equally established tumour suppressor, PTEN, on upregulation via PPARgamma agonist leads to hypoxic apoptosis of pulmonary arterial vascular smooth muscle cells and provides a recent rationale for therapeutics to target pulmonary hypertension [46]. Table 2 summarizes several of these mechanistically shared aspects between cancer and vascular dysregulation seen in hypertension.

Notably, a number of factors, viz: angiotensin II, interleukin-6, endothelin, sphingosine-1-phosphate, chromogranin, enolase and VEGF $[4,5]$ relate to cardiocytoprotection and cancer. Any imbalance in expression of these progrowth factors may
Table 2. Alignment of mechanisms/factors relating cancer to cardiac failure, hypertension and atheroma.

\begin{tabular}{|c|c|}
\hline Cancer & Cardiac failure, hypertension, atheroma \\
\hline DPPIV/SDF ${ }^{a}$ & DPPIV/SDF-heart failure ${ }^{a}$ \\
\hline $\mathrm{p} 53^{b}$ & p53-pulmonary hypertension ${ }^{b}$ \\
\hline $\mathrm{PTEN}^{c}$ & PTEN-pulmonary hypertension ${ }^{c}$ \\
\hline VEGF/NF-kappa $\mathrm{B}^{d}$ & VEGF/NF-kappa B-hypertension ${ }^{d}$ \\
\hline $\begin{array}{l}\text { Interleukin-6 } \\
\text { Chromogranin } \\
\text { Enolase } \\
\text { Endothelin } \\
\text { Sphingosine-1 } \\
\text {-phosphate } \\
\text { Angiogenic factors: } \\
\text { (VEGF/FGF/HGF) }^{e}\end{array}$ & $\begin{array}{l}\text { Prosurvival/progrowth factors- } \\
\text { atheroma/hypertension }^{e}\end{array}$ \\
\hline
\end{tabular}

${ }^{\text {a }}$ Prosurvival SDF (stromal cell-derived factor) levels are regulated in cancer by tumour suppressor DPPIV (dipeptidyl peptidase IV) [40], and in heart failure SDF being prosurvival is beneficial [43] with DPPIV opposing this via SDF degradation.

$\mathrm{b}_{\text {Tumour suppressor, }}$ 53, is involved in inhibition of pulmonary arterial smooth muscle cell growth thus targeting pulmonary hypertension [45].

${ }^{\mathcal{C}}$ Tumour suppressor, PTEN, is also involved in inhibiting pulmonary arterial smooth muscle cell growth and targets pulmonary hypertension [46].

${ }^{\mathrm{d}}$ Prosurvival cancer VEGF/NF-kappa B axis [48] has been considered a target for hypertension [47].

${ }^{\mathrm{e}}$ In addition to their cardiocytoprotective role [4,5], progrowth factors align with hypertension and atheroma formation-reflecting vascular dysfunction.

promote hypertension and vascular dysfunction/atheroma $[4,5]$. Interestingly, in regards the latter factor, VEGF, prosurvival factor NF-kappa B was found to be involved in a novel mechanism regulating VEGF-related stretch-induced cardiac hypertrophy [47]. Here it was stated that: 'Elucidation of this novel mechanism may provide a target for developing future pharmacotherapy to treat hypertension and heart disease.' Notably, the VEGF and linked NF-kappa B prosurvival mechanism was foreshadowed in therapy resistant, relapsing cancer [48] (Table 2). Unsurprisingly, statin treatment, via RhoA prenylation inhibition, induces vascular smooth muscle cell apoptosis thus opening a further therapeutic window for hypertension and atheroma management [49] (see Table 5below). This also aligns with the cancer mechanism [50]. In apoE(-/-) mice which were provided with a Western-type diet, atherosclerotic lesions readily formed [51]. Simvastatin led to an up-regulation of $\mathrm{BCl}-2$ and $\mathrm{BCl}-\mathrm{xL}$ expression which are classical cancer oncogenes and decreased tumour suppressor p53 expression. This statin may therefore be said to prevent apoptosis in the labile atherosclerotic plaque thus potentially leading to plaque stabilization (see Table 5-below). Importantly, this recently uncovered statin-related interplay of established cancer prosurvival/pro-apoptotic factors in the context of atheroma is reflective of the value of comparison of cancer 
mechanisms to the cardiac/vascular context.

Overall, in terms of clinical relevance, therapeutics that shall either promote tumour suppression (anti-growth) or agents that target excessively produced progrowth, proinflammatory factors, may well be able to address hypertension and atheroma (Table 2). The treatment puzzle is made complex by the fact that progrowth factors are in themselves cardioprotective and anti-growth mechanisms may promote cardiac damage and lead to exacerbating heart failure. To aid addressing this, I have already stated the importance for maintaining a balance or homeostasis in regards prosurvival vs pro-apoptotic factors as the key message for clinicians [5].

\section{Addressing cardiac hypertrophy}

In cardiac hypertrophy one would anticipate that prosurvival pathways are unbalanced in favour of excessive progrowth stimuli. Notably, statins target cardiac hypertrophy via inhibition of RhoA geranylgeranylation/prenylation and membrane localization [52] (see Table 5-below). This neatly aligns with the mechanism for statin targeting RhoA in cancer [50].

Hypertrophic-related Ras is pro-growth in the heart and its balancing tumour suppressor, RASSF1A, downregulates the Ras-Raf1-Erk1/2 cardiac circuit - truly a case of 'where the heart and cancer meet' $[2,53]$. It was observed that the relationship between signal paths controlling tumour growth and cardiac hypertrophy (viz: proto-oncogenes positively impacting on the development of hypertrophy) is of very significant interest and importance [53]. Thus appreciating the precise mechanisms involved is key and notably pro-apoptotic factors such as tumour suppressors maintain a balance in regulating hypertrophic signaling and form tangible therapeutic targets for cardiac hypertrophy.

KCNQ1 is a potassium channel protein and aids in cardiomyocyte repolarisation. Already in cancer, it is seen that low expression of KCNQ1 is associated with poor survival and this channel factor is thus classified as a tumour suppressor [54]. Recently [55], in a model for cardiac hypertrophy, a major reduction in expression of KCNQ1 is evident. This is consistent with KCNQ1 as a growth inhibitor antagonizing excessive prosurvival stimulus in the heart. This factor thus forms part of growth control-homeostatic balance-as forecast from cancer. A summary of these relationships is presented in Table 3.

\section{Addressing co-morbidities}

Cardiac and vascular diseases oftentimes present as comorbid conditions. For example, hypertension with cardiac hypertrophy share an imbalance of progrowth mechanisms that cancer also displays (above). Shared pro-apoptotic, antisurvival mechanisms, may explain, for example, such comorbid features as heart failure with aneurysm formation. In this scenario, the transcriptional regulator Kruppel-like factor 15 (KIf15) levels are markedly reduced in heart failure and aortic aneurysm [56]. In Klf15 deficient animal models these
Table 3. Alignment of mechanisms/factors relating cancer and cardiac hypertrophy.

\begin{tabular}{ll}
\hline Cancer & Cardiac hypertrophy \\
\hline RhoA prenylation $^{a}$ & RhoA prenylation $^{a}$ \\
Ras/RASSF1A $^{b}$ & RASSF1A/Ras $^{b}$ \\
KCNQ1 $^{c}$ & KCNQ1 $^{c}$ \\
\hline
\end{tabular}

${ }^{\mathrm{a}} \mathrm{RhoA}$ prenylation is a post-translational prosurvival pathway in cancer [50]-the same mechanism is present in cardiac hypertrophy [52].

${ }^{b} \mathrm{Ras}$ is a noted prosurvival path in cancer and is balanced by its tumour suppressor, RASSF1A [53] with the same mechanism applying in the heart regulating cardiac hypertrophy [53].

${ }^{\mathrm{c}} \mathrm{KCNQ1}$ (a potassium channel factor) is a tumour suppressor [54] and is lowered in cardiac hypertrophy [55].

co-morbid pathologies develop in a p53-dependent and p300 acetyltransferase-dependent manner. Activation of KLF15 inhibits p300-mediated acetylation of p53 and deficiency of prosurvival KIf15 produces hyperacetylation of p53 in heart and aorta. Importantly, p300-mediated p53 acetylation is proving to be a key post-translational modification for $\mathrm{p} 53$ function and is reduced by MDM2 inhibitor [57]. Thus there is a molecular commonality between these co-morbities that rests on a balance between prosurvival/apoptotic regulation via KIf15. Recently, vascular smooth muscle cell apoptosis in aneurysms was related to MDM2 inhibitor reduction with resultant increase in p53 activity [58]. This is reminiscent of MDM2 involvement in regulating p53 in the context of proliferation of pulmonary arterial smooth muscle [45].

Unsurprisingly, this balance in prosurvival/apoptosis has been mechanistically reflected within the context of cancer, where Kruppel-like factor (KIf6) silencing resulted in p53 upregulation and apoptosis in hepatic carcinoma cells [59]. Clearly, the Kruppel-like factor balance of prosurvival/ apoptosis in the cardiac/vascular system is closely mimicked and forecast via cancer.

Not only are co-morbid features recognized within the cardiac and vascular system but also it must be recalled that cardiacvascular diseases are not isolated in their context-they oftentimes present concurrently alongside metabolic disturbances such as insulin resistance and obesity. Proinflammatory factors such as adipocytokines and oncoproteins/prosurvival factors in concert support cardiac hypertrophy and upset homeostatic balance to favour hypertension/atheroma (above). Examples are interleukin-6 and TNFalpha [5]. Further, as TNF and interleukin- 6 relate to atheroma, hypertension and cardiomyopathy, this may be considered an overall excessive 'prosurvival' reaction. These are feature hallmarks of obesityassociated diabetes with the metabolic syndrome. In addition, DPPIV, a cancer tumour suppressor and agent countering cardioprotection (above) and playing a role in heart failure is itself an adipocytokine [60]. This shines a clearer light on the link between obesity/metabolic disease and potentially 
John A. Loudon, Cardiovascular System 2014,

http://www.hoajonline.com/journals/pdf/2052-4358-2-6.pdf

doi: $10.7243 / 2052-4358-2-6$

damaging consequences this has on the cardiac-vascular system. Thus both prosurvival and pro-apoptotic pathways are involved that mimic the cancer context. An overall summary is given in Table 4 .

Table 4. Mechanisms/factors including inflammation relating cancer to cardiac-vascular diseases and co-morbidities.

\begin{tabular}{|c|c|}
\hline Cancer & $\begin{array}{l}\text { Cardiac-vascular diseases/ } \\
\text { Co-morbidities }\end{array}$ \\
\hline Kruppel-like factor/p53 ${ }^{a}$ & $\begin{array}{l}\text { Kruppel-like factor/p53-heart } \\
\text { failure/aneurysm }\end{array}$ \\
\hline Adipocytokine-il-6/TNF ${ }^{b}$ & $\begin{array}{l}\text { il-6/TNF-cardiomyopathy/ } \\
\text { hypertension/atheroma/insulin } \\
\text { resistance/obesity } b\end{array}$ \\
\hline Adipocytokine-DPPIV ${ }^{c}$ & DPPIV-heart failure ${ }^{c}$ \\
\hline $\begin{array}{l}\text { Inflammation: NF-kappaB/ } \\
\text { ox-LDL-LOX1 }\end{array}$ & $\begin{array}{l}\text { Inflammation: } \\
\text { NF-kappaB/ } \\
\text { ox-LDL-LOX1-atheroma }^{d}\end{array}$ \\
\hline
\end{tabular}

${ }^{\mathrm{a}}$ Kruppel-like factor, family member Klf6, downregulates p53 tumour suppressor in the cancer context, thereby providing a prosurvival signal [59]-Kruppel-like factor, family member Klf15, inhibits p53 activation and deficiency of this factor relates to comorbid development of heart failure with aneurysm [56].

${ }^{b}$ Proinflammatory cytokines, such as adipokines interleukinl- 6 and TNF from adipose tissue, may favour a progrowth response (the latter via NF-kappa B activation) relevant in the cancer context and evident in cardiomyopathy/hypertension/atheroma [5] alongside being related to co-morbid features such as obesity/insulin resistance.

${ }^{\mathrm{c}}$ Adipokine DPPIV is a tumour suppressor and counters cardioprotection [60].

${ }^{\mathrm{d}}$ Inflammation forms a notable mechanistic commonality between cancer and cardiac/vascular disease, as exemplified by ox-LDL and its receptor LOX-1 activating the NF-kappa B inflammatory cascade which in turn promotes cancer and atheroma/vascular dysfunction [62].

\section{Addressing inflammation-a common link between cancer and heart diseases}

As I have detailed $[5,6]$, inflammation is a major mechanistic common linkage between many conditions such as atheroma/ vascular disease, cardiac disease, cancer and neurological disease. Obesity and diabetes, important co-morbities of cardiac and vascular diseases, are related to 'metinflammation', or metabolic inflammation, resulting in insulin resistance [61].

Targeting inflammatory response via modulating the NFkappa $\mathrm{B}$ signaling axis-a central player-by such newly'repurposed'immune modulatory agents as Amlexanox may hold significant promise for a multitude of inflammatory-related conditions such as atheroma [6]. Interestingly, the link between cancer and inflammation, and NF-kappa B and atheroma has been strongly underlined with ox-LDL and its receptor LOX-1 [62]. This ligand-receptor complex activates the inflammatory pathway through NF-kappa B leading to cell transformation. LOX-1 maintains the transformed state in a diverse range of
Table 5. The aligning of therapeutics for cancer and cardiac -vascular diseases.

\begin{tabular}{|c|c|}
\hline Cancer & ardiac/vascular \\
\hline $\begin{array}{l}\text { Rho } \\
\mathrm{Bcl}\end{array}$ & $\begin{array}{l}\text { Statin: iNOS/Cox-2/ } \\
\text { S-nitrosylation-infarct sparing }{ }^{a} \\
\text { Statin: hypertension/cardiac } \\
\text { hypertrophy } \\
\text { Statin: Bcl-2-Bcl-xL/p53 atheroma }{ }^{c}\end{array}$ \\
\hline PK & diac \\
\hline $\mathrm{N}^{-1}$ & nypertension \\
\hline Allicin: Nrf2 $f$ & Nrf2-cardiac h \\
\hline \multicolumn{2}{|c|}{$\begin{array}{l}\text { aNOS/Cox-2/S-nitrosylation is prosurvival in cancer [33] and } \\
\text { this pathway may be modulated by statin therapy to lead to } \\
\text { cardioprotection [32]. } \\
\text { bRhoA prenylation, a cancer prosurvival mechanism, may be } \\
\text { targeted by statin therapies to moderate hypertension [49] and } \\
\text { cardiac hypertrophy [52]. }\end{array}$} \\
\hline \multicolumn{2}{|c|}{$\begin{array}{l}\text { 'Cancer prosurvival/oncogenic factors } \mathrm{Bcl}-2 \text { and } \mathrm{Bcl}-\mathrm{xL} \text { and } \\
\text { tumour suppressor p53 may }{ }^{\mathrm{e}} \text { regulated via statin therapeutics to } \\
\text { beneficially increase atheromatous plaque stability [51]. }\end{array}$} \\
\hline \multicolumn{2}{|c|}{$\begin{array}{l}{ }^{\mathrm{d}} \text { Non-steroidal anti-inflammatory agents (NSAIDs) target Cox-2 } \\
\text { and PKC delta, a prosurvival pathway both in cancer [66] and the } \\
\text { heart [65] and interfere with this infarct-sparing mechanism. } \\
\text { Cox-2/EGFR/MAPK signal cascade acts in cancer [67] as well as } \\
\text { being a pro-hypertrophic mechanism in the heart [68]. Following } \\
\text { on, targeting Cox-2 may be beneficial in hypertension [69] and } \\
\text { atheroma/vascular dysfunction [70]. }\end{array}$} \\
\hline \multicolumn{2}{|c|}{$\begin{array}{l}\text { The omega- } 3 \text { polyunsaturate Docosahexaenoate, DHA, } \\
\text { downregulates Cox-2 and NF-kappa B prosurvival signaling } \\
\text { axis in cancer [72] via the arachidonic lipoxygenase Lox [73]. } \\
\text { In the vascular system, DHA counters prosurvival mechanisms } \\
\text { in hypertension [74] and by downregulating Cox-2/NF-kappa B } \\
\text { prosurvival axis also counters atheroma formation [71] notably via } \\
\text { the metabolic products of Lox. }\end{array}$} \\
\hline
\end{tabular}

cancers and supports tumor growth. Upregulation of LOX-1 by ox-LDL is connected to endothelial cell dysfunction, smooth muscle cell growth and migration seen in atheroma and these are all matching features of the tumourigenic phenotype. It was stated: 'As in atherosclerosis, ox-LDL and its receptor LOX-1 activate the inflammatory pathway through nuclear factor-kappa $B$, leading to cell transformation.' [62] (Table 4). This leaves no doubt in respecting the tight relation between cancer and vascular disease-a theme that I have portrayed in extending to cardiac and vascular diseases generally (Figure 1).

\section{Addressing therapeutics}

One of the central aspects arising from the close relation between 


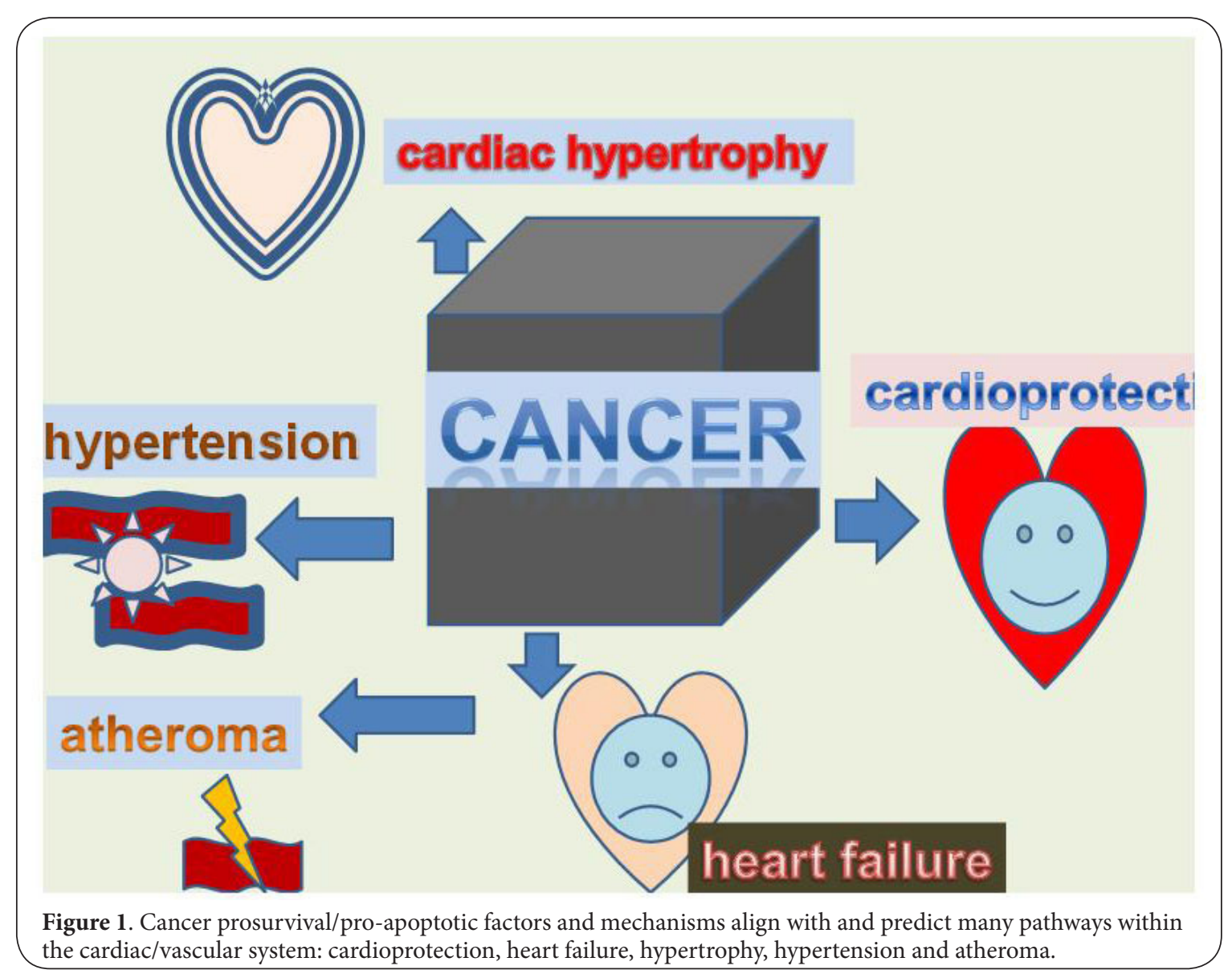

heart and cancer prosurvival and apoptotic mechanisms is the fact that agents targeting cancer shall have a detrimental effect on cardiomyocyte physiology [2]. This defines the relatively new field of cardio-oncology [63]. Recently, it was indicated that human epidermal growth factor receptor-2 (HER2) signaling is prosurvival not only in mammary gland carcinoma but also is a matching prosurvival mechanism in cardiomyocytes [64]. Thus, toxicity towards the heart is certainly a negative issue in terms of employing HER2 targeted therapeutics for cancer. Means to optimize such anti-cancer therapeutics were considered through screening against induced pluripotent stem cells in an attempt to idealize cancer therapy selection on an individual patient (personalised medicine) basis [64].

The relation of statins to mechanisms involved in cancer may be usefully adapted for cardiac and vascular disease therapeutics-a theme pursued throughout this article. For example, Atorvastatin induces cardioprotection and is infarctsparing via cancer mechanisms [32]. Further, statin therapy may, via RhoA prenylation inhibition, a cancer therapeutic target, result in vascular smooth muscle cell programmed cell death, thence delivering prospective therapeutics for vascular diseases such as hypertension [49]. Simvastatin, by increasing expression of $\mathrm{BCl}-2$ and $\mathrm{BCl}-\mathrm{xL}$ prosurvival oncogenic factors, and diminishing levels of tumour suppressor p53 expression, targets labile atherosclerotic plaques leading to plaque stabilization [51]. In respect to cardiac hypertrophy, statin therapy via targeted inhibition of RhoA geranylgeranylation/ prenylation and membrane localization-a cancer prosurvival mechanism-addresses a means to combat cardiac hypertrophy [52].

The established non-steroidal anti-inflammatory (NSAID) drug target, Cox-2, is highly relevant to my discussion of cardiac and vascular diseases and cancer overall. It is understood that Cox-2 is cardioprotective and prosurvival factor in cancer [2]. Anti-inflammatory agents such as NSAIDs logically increase cardiac risk status as these drugs target Cox-2. Mechanistically, Cox-2 is cardiocytoprotective via PKC delta [65]-a mechanism involving Cox-2/PKC delta as foretold by cancer [66]. Further, the prosurvival cascade involving EGFR, Cox-2 and MAPK acts in cancer [67] and again foretells the mechanism for prohypertrophic cardiac signaling involving Cox-2/EGFR/MAPK [68]. In the vascular system, Cox-2 is also prosurvival, thus targeting Cox-2 may alleviate pulmonary hypertension [69]. In atherogenesis, prosurvival Cox-2 is involved as a mediator. Somewhat predictably, it is involved in endothelial dysfunction/resistance to apoptosis seen in diabetic vasculature for example [70]. Along with TNFalpha 
John A. Loudon, Cardiovascular System 2014,

and interleukin-6, prosurvival Cox-2 forms a therapeutic target for anti-atherogenic therapies.

Further, in terms of relevance to Cox-2 mechanisms, are dietary polyunsaturated fatty acids, which may be considered broadly speaking as potential therapeutic agents in their own right. The omega-3 polyunsaturate docosahexaenoate (DHA) targets and inhibits Cox-2 along with NF-kappa B and thus reduces pro-inflammatory stimuli for atheroma development [71]. Specifically, the arachidonic lipoxygenase 15-LOX-1 metabolizes DHA, with the products of which act to downregulate Cox-2. In parallel with this observation, DHA downregulates Cox-2 and NF-kappa B in cancer [72] and the 15-LOX-1 metabolites are noted in particular in this respect [73]. Unsurprisingly, of late, DHA as an anti-growth factor is found to counter hypertension [74]. Having said this, and understanding the prosurvival mechanisms targeted by DHA from cancer, it is to be anticipated that DHA may well fail in terms of prevention of heart disease overall - a conclusion that is becoming apparent [75]-hence limiting DHA as a therapy in itself. This may be understood in light of the notion that DHA potentially targets prosurvival mechanisms in cardiomyocytes, thus countering any potential benefit to be gained from its vascular effects. This scenario underscores the importance of viewing the cardiac and vascular systems as two parts of one whole [5] when cross-comparing to cancer prosurvival mechanisms.

Other more novel therapeutics stem from considering the concept linking heart and cancer mechanistically. It is noted that increasing cellular signaling factor CAMP via phosphodiesterase III (PDEIII) targeting with cilostazol acts in concert with a DPPIV inhibitor, MK0626, in cardioprotection [76]. These effects in the diabetic disease model are associated with increase in cardiomyocyte cAMP levels and PKA activity and downregulation of tumour suppressor PTEN level alongside downstream oncogenic prosurvival cascade activation. Amlexanox, an agent employed for decades as an immunemodulator [6], via targeting NF-kappa B noncanonical kinases TBK1 and ikkepsilon, reduces activation of the adipocyte phosphodiesterase, PDE3B. Thus Amlexanox therapy is capable in the animal model to restore PKA signaling and augment CAMP in adipocytes [77] similar to the infarct sparing cardiomyocyte mechanism in diabetes [76]. In this regard, its ability to target adipose tissue thus countering obesity and thereby have an impact on insulin-resistance lends a major future potential for this novel 'repurposed' agent for management of obesity/diabetes-related cardiac/ vascular disease.

An interesting further potential addition to the therapeutic armamentarium is the agent Allicin, (diallyl thiosulfinate), an active component in freshly crushed garlic [78]. This counteracts cardiac hypertrophic changes by decreasing levels of reactive oxygen species. Allicin significantly increased mRNA expression and protein levels of Nrf2- antioxidant signaling pathway. Notably, Allicin has been shown to act through enhancing Nrf2 levels in cancer to induce apoptosis and forms an anti-survival strategy in that context [79]. Hence cancer studies foretold Allicin's mechanism to reduce an imbalance in progrowth stimulus leading to cardiac hypertrophy. Table 5 outlines shared therapeutics between cancer and cardiac/ vascular diseases.

\section{Conclusion}

As was stated earlier [80], atheroma and cardiac disease such as hypertrophy and ultimate heart failure is notably in part due to a series of unbalanced growth promoting activities in the system as a whole - the 'coronary hypothesis in hypertension'. Blood pressure lowering alone does not reverse cardiac pathology in itself and this prompts a totalistic approach- directing attention to the overall imbalance in cardiac and vascular homeostasis [5]. Disease-related imbalances and mechanisms involved in growth promotion versus inhibition in the cardiac-vascular system may be forecast from studying cancer. The aim of this article is to bring to the foreground this much overlooked strategic approach. As a reflection of this association, it has been recently stated in regards pulmonary arterial hypertension (PAH): "...PAH shares common aberrantly activated pathways with cancers that lead to proliferation and survival of pulmonary arterial smooth muscle cells, among others, within the artery wall and narrowing the lumen" [81]. Therefore, cancer pro-growth factors not only align with cardioprotection but also are pro-hypertensive/atherogenic/cardiohypertrophic. In the field of cardio-oncology, it is emphasized that by targeting cancer one may also be targeting the heart/ vascular system $[2,64]$. Clinicians need to be clearly aware of this firm relation between the two since prosurvival/antisurvival mechanisms between heart/vascular system and cancer align. By taking the mechanistic 'cue' from cancer, one may bring forward novel therapeutics into cardiac and vascular medicine. My contention is that the highly sought after'holy grail' of understanding cardioprotective mechanisms along with improved appreciation of vascular/heart disease overall may well be greatly facilitated via a detailed crossexamination of cancer itself.

\section{Competing interests}

The author declares that he has no competing interests.

\section{Acknowledgement}

I thank my mother for her many useful discussions during the course of preparation of this article and the reviewing panel for their helpful suggestions which have improved the presentation.

\section{Publication history}

Editors: Waeber Bernard, University Hospital of Lausanne, Switzerland. Michael S. Wolin, New York Medical College, USA.

Senior Editor: Shiwei Duan, Ningbo University, China.

Received: 12-May-2014 Final Revised: 30-Jun-2014

Accepted: 04-Jul-2014 Published: 11-Jul-2014 


\section{References}

1. Szucs G, Murlasits Z, Torok S, Kocsis GF, Paloczi J, Gorbe A, Csont T, Csonka $\mathrm{C}$ and Ferdinandy P. Cardioprotection by farnesol: role of the mevalonate pathway. Cardiovasc Drugs Ther. 2013; 27:269-77. | Article | PubMed

2. Loudon JA. A novel prosurvival model for cancer under environmental challenge: the "heart-felt" message for therapeutic intervention. Oncol Res. 2011; 19:407-43. | Article | PubMed

3. Loudon JA. Harvesting the Benefits of Understanding Cancer with the Use of 'Shuttle' Era Technology- Cellular Survival Strategies and Tissue Engineering Via Grafting of Genetically Immortalized Autologous Cells. J Bioanal Biomed. 2011; S5:001. I Article

4. Loudon JA. Cancer may lend key clues for cardiovascular risk analysis. Cardiovasc Drugs Ther. 2013; 27:255-6. I Article | PubMed

5. Loudon JA. Two sides of the one coin-the cardiac and vascular system. Cardiovasc Drugs Ther. 2014; 28:199-201. | Article | PubMed

6. Loudon JA. Preventing and Correcting Communicable and NonCommunicable Chronic Disease via Amlexanox - Dual 'No-Nonsense' and Inflammatory Axis Targeting. J Bioanal Biomed 2013; 5:138-179. I Article

7. Swanson DR. Medical literature as a potential source of new knowledge. Bull Med Libr Assoc. 1990; 78:29-37. I PubMed Abstract I PubMed Full $\underline{\text { Text }}$

8. Yano K. Lipid metabolic pathways as lung cancer therapeutic targets: a computational study. Int J Mol Med. 2012; 29:519-29. | Article | PubMed Abstract | PubMed Full Text

9. Dinsmore $\mathrm{CJ}$ and Bell IM. Inhibitors of farnesyltransferase and geranylgeranyltransferase-I for antitumor therapy: substrate-based design, conformational constraint and biological activity. Curr Top Med Chem. 2003; 3:1075-93. I Article I PubMed

10. Hamadmad SN and Hohl RJ. Lovastatin suppresses erythropoietin receptor surface expression through dual inhibition of glycosylation and geranylgeranylation. Biochem Pharmacol. 2007; 74:590-600. | Article | PubMed

11. Kapusta L, Zucker N, Frenckel G, Medalion B, Ben Gal T, Birk E, Mandel H, Nasser N, Morgenstern S, Zuckermann A, Lefeber DJ, de Brouwer A, Wevers RA, Lorber A and Morava E. From discrete dilated cardiomyopathy to successful cardiac transplantation in congenital disorders of glycosylation due to dolichol kinase deficiency (DK1-CDG). Heart Fail Rev. 2013; 18:187-96. I Article I PubMed Abstract | PubMed Full Text

12. Blum R, Cox AD and Kloog Y. Inhibitors of chronically active ras: potential for treatment of human malignancies. Recent Pat Anticancer Drug Discov. 2008; 3:31-47. | Article | PubMed

13. Joo JH and Jetten AM. Molecular mechanisms involved in farnesolinduced apoptosis. Cancer Lett. 2010; 287:123-35. I Article I PubMed Abstract I PubMed Full Text

14. Ito T, Kawata S, Tamura S, Igura T, Nagase T, Miyagawa JI, Yamazaki E, Ishiguro $H$ and Matasuzawa Y. Suppression of human pancreatic cancer growth in BALB/c nude mice by manumycin, a farnesyl:protein transferase inhibitor. Jpn J Cancer Res. 1996; 87:113-6. | Article | PubMed

15. Brar BK, Jonassen AK, Egorina EM, Chen A, Negro A, Perrin MH, Mjos OD, Latchman DS, Lee KF and Vale W. Urocortin-II and urocortin-III are cardioprotective against ischemia reperfusion injury: an essential endogenous cardioprotective role for corticotropin releasing factor receptor type 2 in the murine heart. Endocrinology. 2004; 145:24-35. | Article I PubMed

16. Turkson J, Bowman T, Adnane J, Zhang Y, Djeu JY, Sekharam M, Frank DA, Holzman LB, Wu J, Sebti S and Jove R. Requirement for Ras/ Rac1-mediated p38 and c-Jun N-terminal kinase signaling in Stat3 transcriptional activity induced by the Src oncoprotein. Mol Cell Biol. 1999; 19:7519-28. | Article | PubMed Abstract | PubMed Full Text

17. Xiang SY, Vanhoutte D, Del Re DP, Purcell NH, Ling H, Banerjee I, Bossuyt J, Lang RA, Zheng Y, Matkovich SJ, Miyamoto S, Molkentin JD, Dorn GW, 2nd and Brown JH. RhoA protects the mouse heart against ischemia/ reperfusion injury. J Clin Invest. 2011; 121:3269-76. | Article | PubMed Abstract | PubMed Full Text

18. Qiang YW, Yao L, Tosato G and Rudikoff S. Insulin-like growth factor I induces migration and invasion of human multiple myeloma cells. Blood. 2004; 103:301-8. I Article I PubMed

19. Cheong SL, Federico S, Venkatesan G, Mandel AL, Shao YM, Moro S, Spalluto $G$ and Pastorin $G$. The $A 3$ adenosine receptor as multifaceted therapeutic target: pharmacology, medicinal chemistry, and in silico approaches. Med Res Rev. 2013; 33:235-335. I Article I PubMed

20. Hussain A, Gharanei AM, Nagra AS and Maddock HL. Caspase inhibition via $A 3$ adenosine receptors: a new cardioprotective mechanism against myocardial infarction. Cardiovasc Drugs Ther. 2014; 28:19-32. I Article I PubMed

21. Gessi S, Merighi S, Varani K, Cattabriga E, Benini A, Mirandola P, Leung E, Mac Lennan S, Feo C, Baraldi S and Borea PA. Adenosine receptors in colon carcinoma tissues and colon tumoral cell lines: focus on the $A(3)$ adenosine subtype. J Cell Physiol. 2007; 211:826-36. I Article I PubMed

22. Tanaka K, Kersten JR and Riess ML. Opioid-Induced Cardioprotection. Curr Pharm Des. 2014. I Article I PubMed

23. Zhang YF, Xu QX, Liao LD, Xu XE, Wu JY, Shen J, Wu ZY, Shen JH, Li EM and $\mathrm{Xu}$ LY. kappa-Opioid receptor in the nucleus is a novel prognostic factor of esophageal squamous cell carcinoma. Hum Pathol. 2013; 44:1756-65. | Article | PubMed

24. Wang CY, Guttridge DC, Mayo MW and Baldwin AS, Jr. NF-kappaB induces expression of the $\mathrm{BCl}-2$ homologue $\mathrm{A} 1 / \mathrm{Bfl}-1$ to preferentially suppress chemotherapy-induced apoptosis. Mol Cell Biol. 1999; 19:5923-9. | Article | PubMed Abstract | PubMed Full Text

25. Sakuma H, Yamamoto M, Okumura M, Kojima T, Maruyama T and Yasuda $\mathrm{K}$. High glucose inhibits apoptosis in human coronary artery smooth muscle cells by increasing bcl-xL and bfl-1/A1. Am J Physiol Cell Physiol. 2002; 283:C422-8. I Article I PubMed

26. Iwata A, Morgan-Stevenson V, Schwartz B, Liu L, Tupper J, Zhu X, Harlan $J$ and Winn R. Extracellular BCL2 proteins are danger-associated molecular patterns that reduce tissue damage in murine models of ischemia-reperfusion injury. PLoS One. 2010; 5:e9103. | Article | PubMed Abstract | PubMed Full Text

27. Stein AB, Bolli R, Dawn B, Sanganalmath SK, Zhu Y, Wang OL, Guo $\mathrm{Y}$, Motterlini $R$ and Xuan YT. Carbon monoxide induces a late preconditioning-mimetic cardioprotective and antiapoptotic milieu in the myocardium. J Mol Cell Cardiol. 2012; 52:228-36. I Article I PubMed

28. Espinoza JL, Takami A, Trung LQ, Kato S and Nakao S. Resveratrol prevents EBV transformation and inhibits the outgrowth of EBVimmortalized human B cells. PLoS One. 2012; 7:e51306. | Article | PubMed Abstract | PubMed Full Text

29. Maarman G, Marais E, Lochner A and du Toit EF. Effect of chronic CPT-1 inhibition on myocardial ischemia-reperfusion injury (I/R) in a model of diet-induced obesity. Cardiovasc Drugs Ther. 2012; 26:205-16. | Article I PubMed

30. Rotondo D and Davidson J. Genetics and molecular biology: fatty acid metabolism in cancer cell survival; carnitine palmitoyltransferase- 1 as a critical anticancer target. Curr Opin Lipidol. 2011; 22:428-9. | Article | PubMed

31. Bandyopadhyay S, Zhan R, Wang Y, Pai SK, Hirota S, Hosobe S, Takano Y, Saito K, Furuta E, liizumi M, Mohinta S, Watabe M, Chalfant C and Watabe K. Mechanism of apoptosis induced by the inhibition of fatty acid synthase in breast cancer cells. Cancer Res. 2006; 66:5934-40. | Article I PubMed

32. Atar S, Ye Y, Lin Y, Freeberg SY, Nishi SP, Rosanio S, Huang MH, Uretsky BF, Perez-Polo JR and Birnbaum Y. Atorvastatin-induced cardioprotection is mediated by increasing inducible nitric oxide synthase and consequent S-nitrosylation of cyclooxygenase-2. Am J Physiol Heart Circ Physiol. 2006; 290:H1960-8. | Article | PubMed

33. Switzer CH, Glynn SA, Cheng RY, Ridnour LA, Green JE, Ambs S and Wink DA. S-nitrosylation of EGFR and Src activates an oncogenic signaling network in human basal-like breast cancer. Mol Cancer Res. 2012; 10:1203-15. | Article | PubMed Abstract | PubMed Full Text 
John A. Loudon, Cardiovascular System 2014,

34. Sun J, Aponte AM, Kohr MJ, Tong G, Steenbergen C and Murphy E. Essential role of nitric oxide in acute ischemic preconditioning: S-nitros(yl)ation versus sGC/cGMP/PKG signaling? Free Radic Biol Med. 2013; 54:105-12. | Article | PubMed Abstract | PubMed Full Text

35. Wong JC, Bathina M and Fiscus RR. Cyclic GMP/protein kinase G typeIalpha (PKG-Ialpha) signaling pathway promotes CREB phosphorylation and maintains higher c-IAP1, livin, survivin, and Mcl-1 expression and the inhibition of PKG-lalpha kinase activity synergizes with cisplatin in non-small cell lung cancer cells. J Cell Biochem. 2012; 113:3587-98. | Article | PubMed

36. Xiang SY, Ye LL, Duan LL, Liu LH, Ge ZD, Auchampach JA, Gross GJ and Duan DD. Characterization of a critical role for CFTR chloride channels in cardioprotection against ischemia/reperfusion injury. Acta Pharmacol Sin. 2011; 32:824-33. | Article | PubMed Abstract | PubMed Full Text

37. Petraccia L, Onori P, Sferra R, Lucchetta MC, Liberati G, Grassi M and Gaudio E. [MDR (multidrug resistance) in hepatocarcinoma clinicaltherapeutic implications]. Clin Ter. 2003; 154:325-35. | Article | PubMed

38. Gross GJ, Hsu A, Nithipatikom K, Pfeiffer AW, Bobrova I and Bissessar E. Acute and chronic cardioprotection by the enkephalin analogue, Eribis peptide 94 , is mediated via activation of nitric oxide synthase and adenosine triphosphate-regulated potassium channels. Pharmacology. 2012; 90:110-6. | Article | PubMed Abstract | PubMed Full Text

39. Ru Q, Tian X, Wu YX, Wu RH, Pi MS and Li CY. Voltage-gated and ATP-sensitive $\mathrm{K}+$ channels are associated with cell proliferation and tumorigenesis of human glioma. Oncol Rep. 2014; 31:842-8. | Article | PubMed

40. Mizokami Y, Kajiyama H, Shibata K, Ino K, Kikkawa F and Mizutani S. Stromal cell-derived factor-1alpha-induced cell proliferation and its possible regulation by CD26/dipeptidyl peptidase IV in endometrial adenocarcinoma. Int J Cancer. 2004; 110:652-9. | Article | PubMed

41. Mascarenhas AK, Allen CM and Loudon J. The association between Viadent use and oral leukoplakia. Epidemiology. 2001; 12:741-3. | Article | PubMed

42. Sedo A, Malik R, Vicar J, Simanek V and Ulrichova J. Quaternary benzo[c] phenanthridine alkaloids as inhibitors of dipeptidyl peptidase IV-like activity baring enzymes in human blood plasma and glioma cell lines. Physiol Res. 2003; 52:367-72. I Pdf I PubMed

43. Kanki S, Segers VF, Wu W, Kakkar R, Gannon J, Sys SU, Sandrasagra A and Lee RT. Stromal cell-derived factor-1 retention and cardioprotection for ischemic myocardium. Circ Heart Fail. 2011; 4:509-18. | Article | PubMed

44. Davidson SM, Selvaraj P, He D, Boi-Doku C, Yellon RL, Vicencio JM and Yellon DM. Remote ischaemic preconditioning involves signalling through the SDF-1alpha/CXCR4 signalling axis. Basic Res Cardiol. 2013; 108:377. I Article | PubMed

45. Mouraret N, Marcos E, Abid S, Gary-Bobo G, Saker M, Houssaini A, Dubois-Rande JL, Boyer L, Boczkowski J, Derumeaux G, Amsellem V and Adnot S. Activation of lung $\mathrm{p} 53$ by Nutlin-3a prevents and reverses experimental pulmonary hypertension. Circulation. 2013; 127:1664-76. | Article | PubMed Abstract | PubMed Full Text

46. Pi WF, Guo XJ, Su LP and Xu WG. Troglitazone upregulates PTEN expression and induces the apoptosis of pulmonary artery smooth muscle cells under hypoxic conditions. Int J Mol Med. 2013; 32:1101-9. I Article | PubMed

47. Leychenko A, Konorev E, Jijiwa M and Matter ML. Stretch-induced hypertrophy activates NFkB-mediated VEGF secretion in adult cardiomyocytes. PLoS One. 2011; 6:e29055. | Article | PubMed Abstract I PubMed Full Text

48. Zhou Y, Yau C, Gray JW, Chew K, Dairkee SH, Moore DH, Eppenberger U, Eppenberger-Castori S and Benz CC. Enhanced NF kappa B and AP-1 transcriptional activity associated with antiestrogen resistant breast cancer. BMC Cancer. 2007; 7:59. | Article | PubMed Abstract | PubMed Full Text

49. Blanco-Colio LM, Villa A, Ortego M, Hernandez-Presa MA, Pascual A, Plaza JJ and Egido J. 3-Hydroxy-3-methyl-glutaryl coenzyme A reductase inhibitors, atorvastatin and simvastatin, induce apoptosis of vascular smooth muscle cells by downregulation of Bcl-2 expression and Rho A prenylation. Atherosclerosis. 2002; 161:17-26. | Article | PubMed

50. Kusama T, Mukai M, Iwasaki T, Tatsuta M, Matsumoto $\mathrm{Y}$, Akedo $\mathrm{H}$ and Nakamura $\mathrm{H}$. Inhibition of epidermal growth factor-induced RhoA translocation and invasion of human pancreatic cancer cells by 3-hydroxy-3-methylglutaryl-coenzyme a reductase inhibitors. Cancer Res. 2001; 61:4885-91. | Article | PubMed

51. Qin W, Lu Y, Zhan C, Shen T, Dou L, Man Y, Wang S, Xiao C, Bian Y and Li J. Simvastatin suppresses apoptosis in vulnerable atherosclerotic plaques through regulating the expression of $\mathrm{p}(53), \mathrm{Bcl}-2$ and $\mathrm{Bcl}-\mathrm{xL}$. Cardiovasc Drugs Ther. 2012; 26:23-30. | Article | PubMed

52. Ogata Y, Takahashi M, Takeuchi K, Ueno S, Mano H, Ookawara S, Kobayashi $E$, Ikeda $U$ and Shimada K. Fluvastatin induces apoptosis in rat neonatal cardiac myocytes: a possible mechanism of statin-attenuated cardiac hypertrophy. J Cardiovasc Pharmacol. 2002; 40:907-15. | Article I PubMed

53. Oceandy D, Cartwright EJ and Neyses L. Ras-association domain family member 1A (RASSF1A)-where the heart and cancer meet. Trends Cardiovasc Med. 2009; 19:262-7. | Article | PubMed

54. Than BL, Goos JA, Sarver AL, O'Sullivan MG, Rod A, Starr TK, Fijneman RJ, Meijer GA, Zhao L, Zhang Y, Largaespada DA, Scott PM and Cormier RT. The role of KCNQ1 in mouse and human gastrointestinal cancers. Oncogene. 2013. | Article | PubMed

55. Uesugi M, Ojima A, Taniguchi T, Miyamoto N and Sawada K. Low-density plating is sufficient to induce cardiac hypertrophy and electrical remodeling in highly purified human iPS cell-derived cardiomyocytes. $J$ Pharmacol Toxicol Methods. 2014; 69:177-88. | Article | PubMed

56. Haldar SM, Lu Y, Jeyaraj D, Kawanami D, Cui Y, Eapen SJ, Hao C, Li Y, Doughman YQ, Watanabe M, Shimizu K, Kuivaniemi H, Sadoshima J, Margulies KB, Cappola TP and Jain MK. KIf15 deficiency is a molecular link between heart failure and aortic aneurysm formation. Sci Trans/ Med. 2010; 2:26ra26. | Article | PubMed Abstract | PubMed Full Text

57. Ito A, Lai CH, Zhao X, Saito S, Hamilton MH, Appella E and Yao TP. p300/ CBP-mediated $\mathrm{p} 53$ acetylation is commonly induced by $\mathrm{p} 53$-activating agents and inhibited by MDM2. EMBO J. 2001; 20:1331-40. | Article | PubMed Abstract | PubMed Full Text

58. Leeper NJ, Raiesdana A, Kojima Y, Kundu RK, Cheng H, Maegdefessel L, Toh R, Ahn GO, Ali ZA and Anderson DR et al. Loss of CDKN2B promotes p53-dependent smooth muscle cell apoptosis and aneurysm formation. Arterioscler Thromb Vasc Biol. 2013; 33:e1-e10. | Article | PubMed Abstract | PubMed Full Text

59. Sirach E, Bureau C, Peron JM, Pradayrol L, Vinel JP, Buscail L and Cordelier P. KLF6 transcription factor protects hepatocellular carcinoma-derived cells from apoptosis. Cell Death Differ. 2007; 14:1202-10. | Article | PubMed

60. Lamers D, Famulla S, Wronkowitz N, Hartwig S, Lehr S, Ouwens DM, Eckardt K, Kaufman JM, Ryden M, Muller S, Hanisch FG, Ruige J, Arner P, Sell $\mathrm{H}$ and Eckel J. Dipeptidyl peptidase 4 is a novel adipokine potentially linking obesity to the metabolic syndrome. Diabetes. 2011; 60:1917-25. | Article | PubMed Abstract | PubMed Full Text

61. Calay ES and Hotamisligil GS. Turning off the inflammatory, but not the metabolic, flames. Nat Med. 2013; 19:265-7. | Article | PubMed

62. Lu J, Mitra S, Wang X, Khaidakov M and Mehta JL. Oxidative stress and lectin-like ox-LDL-receptor LOX-1 in atherogenesis and tumorigenesis. Antioxid Redox Signal. 2011; 15:2301-33. | Article | PubMed

63. Hong RA, limura T, Sumida KN and Eager RM. Cardio-oncology/oncocardiology. Clin Cardiol. 2010; 33:733-7. | Article | PubMed

64. Zhu S, Cawley SM, Bloch KD and Huang PL. Trastuzumab and lapatinib differ in effects on calcium cycling and HER2 expression in human embryonic stem cell-derived cardiomyocytes. Cardio Vasc Syst. 2013; 1:10. | Article

65. Kwak HJ, Park KM, Choi HE, Lim HJ, Park JH and Park HY. The cardioprotective effects of zileuton, a 5-lipoxygenase inhibitor, are mediated by COX-2 via activation of PKC delta. Cell Signal. 2010; 22:807. | Article | PubMed

66. Xu K, Chang CM, Gao H and Shu HK. Epidermal growth factor-dependent cyclooxygenase-2 induction in gliomas requires protein kinase C-delta. Oncogene. 2009; 28:1410-20. | Article | PubMed 
John A. Loudon, Cardiovascular System 2014,

67. Yoon JH, Higuchi H, Werneburg NW, Kaufmann SH and Gores GJ. Bile acids induce cyclooxygenase-2 expression via the epidermal growth factor receptor in a human cholangiocarcinoma cell line. Gastroenterology. 2002; 122:985-93. | Article | PubMed

68. Mendez M and LaPointe MC. PGE2-induced hypertrophy of cardiac myocytes involves EP4 receptor-dependent activation of p42/44 MAPK and EGFR transactivation. Am J Physiol Heart Circ Physiol. 2005; 288:H2111-7. | Article | PubMed

69. Kylhammar D and Radegran G. Cyclooxygenase-2 inhibition and thromboxane $A(2)$ receptor antagonism attenuate hypoxic pulmonary vasoconstriction in a porcine model. Acta Physiol (Oxf). 2012; 205:50719. | Article | PubMed

70. Redondo S, Ruiz E, Gordillo-Moscoso A, Navarro-Dorado J, Ramajo $M$, Rodriguez $E$, Reguillo $F$, Carnero $M$, Casado $M$ and Tejerina $T$. Overproduction of cyclo-oxygenase-2 (COX-2) is involved in the resistance to apoptosis in vascular smooth muscle cells from diabetic patients: a link between inflammation and apoptosis. Diabetologia. 2011; 54:190-9. | Article | PubMed

71. Massaro M, Habib A, Lubrano L, Del Turco S, Lazzerini G, Bourcier T, Weksler BB and De Caterina R. The omega-3 fatty acid docosahexaenoate attenuates endothelial cyclooxygenase-2 induction through both NADP(H) oxidase and PKC epsilon inhibition. Proc Natl Acad Sci U S A. 2006; 103:15184-9. | Article | PubMed Abstract | PubMed Full Text

72. Horia $E$ and Watkins BA. Complementary actions of docosahexaenoic acid and genistein on COX-2, PGE2 and invasiveness in MDA-MB-231 breast cancer cells. Carcinogenesis. 2007; 28:809-15. | Article | PubMed

73. Janakiram NB and Rao CV. Role of lipoxins and resolvins as antiinflammatory and proresolving mediators in colon cancer. Curr Mol Med. 2009; 9:565-79. | Article | PubMed

74. Yan J, Chen R, Liu P and Gu Y. Docosahexaenoic acid inhibits development of hypoxic pulmonary hypertension: in vitro and in vivo studies. Int J Cardiol. 2013; 168:4111-6. | Article | PubMed

75. Peskin BS. Why fish oil fails: a comprehensive 21st century lipids-based physiologic analysis. J Lipids. 2014; 2014:495761. | Article | PubMed Abstract | PubMed Full Text

76. Birnbaum Y, Castillo AC, Qian J, Ling S, Ye H, Perez-Polo JR, Bajaj M and Ye Y. Phosphodiesterase III inhibition increases cAMP levels and augments the infarct size limiting effect of a DPP-4 inhibitor in mice with type-2 diabetes mellitus. Cardiovasc Drugs Ther. 2012; 26:445-56. | Article | PubMed

77. Mowers J, Uhm M, Reilly SM, Simon J, Leto D, Chiang SH, Chang L and Saltiel AR. Inflammation produces catecholamine resistance in obesity via activation of PDE3B by the protein kinases IKK\{varepsilon\} and TBK1. Elife. 2013; 2:e01119. | Article | PubMed Abstract | PubMed Full $\underline{\text { Text }}$

78. Li XH, Li CY, Xiang ZG, Hu JJ, Lu JM, Tian RB and Jia W. Allicin ameliorates cardiac hypertrophy and fibrosis through enhancing of Nrf2 antioxidant signaling pathways. Cardiovasc Drugs Ther. 2012; 26:457-65. | Article | PubMed

79. Bat-Chen W, Golan T, Peri I, Ludmer Z and Schwartz B. Allicin purified from fresh garlic cloves induces apoptosis in colon cancer cells via Nrf2. Nutr Cancer. 2010; 62:947-57. | Article | PubMed

80. Weber MA. Coronary heart disease and hypertension. Am J Hypertens. 1994; 7:146S-153S. | Article | PubMed

81. Meloche J, Paulin R, Provencher S and Bonnet S. Therapeutic Potential of microRNA Modulation in Pulmonary Arterial Hypertension. Curr Vasc Pharmacol. 2013. | Pdf | PubMed

\section{Citation:}

Loudon JA. Viewing cancer pathophysiology as a lead in understanding cardiac and vascular disease mechanisms. Cardio Vasc Syst. 2014; 2:6.

http://dx.doi.org/10.7243/2052-4358-2-6 